\title{
Strategi Komunikasi Pemasaran Pengusaha Brand Lokal (Studi Kasus Pada Fine Finest Hour Dan Your Apparel)
}

\author{
Reynaldi Permana dan Roswita Oktavianti \\ Nikolas.reynaldi12@gmail.com Roswitao@fikom.untar.ac.id \\ Fakultas Ilmu Komunikasi Universitas Tarumanagara
}

\begin{abstract}
The development of the era was marked by information and communication technology that was already sophisticated. Age development can be used as a tool for developing communication strategies. Fine Finest Hour and Your Apparel are local clothing brands that use several marketing communication strategies and marketing mixes. This study aims to determine the communication strategies used by local clothing brand entrepreneurs in product marketing. This research is a qualitative research. The method used in this study is a case study. Data collection in this study uses interview methods with the brand owners of Fine Finest Hour and Your Apparel and several consumers from each company, literature studies and indirect observations. From all marketing activities, the activities that are most dominant are considered by the two companies, namely choosing communication channels and measuring results. Communication with customers is done face to face, through social media, and other electronic media. Customer satisfaction is measured by viewing comments via Instagram social media, there is also a product review column from Tokopedia.
\end{abstract}

Keyword: Communication Strategy, Local Brand, Marketing Communication

\begin{abstract}
Abstrak
Berkembangnya zaman ditandai dengan teknologi informasi dan komunikasi yang sudah canggih. Perkembangan zaman dapat digunakan sebagai alat untuk menyusun strategi komunikasi. Fine Finest Hour dan Your Apparel adalah brand clothing lokal yang menggunakan beberapa strategi komunikasi pemasaran dan bauran pemasaran. Penelitian ini bertujuan untuk mengetahui strategi komunikasi yang digunakan oleh pengusaha brand clothing lokal dalam pemasaran produk. Penelitian ini merupakan penelitian kualitatif. Metode yang digunakan pada penelitian ini yaitu studi kasus. Pengumpulan data pada penelitian ini menggunakan metode wawancara dengan pemilik brand Fine Finest Hour dan Your Apparel dan beberapa konsumen dari masing-masing perusahaan, studi pustaka dan observasi secara tidak langsung. Dari seluruh kegiatan pemasaran yang diteliti menunjukkan bahwa kegiatan yang paling dominan diperhatikan oleh kedua perusahaan yaitu memilih saluran komunikasi dan mengukur hasil. Komunikasi dengan pelanggan dilakukan secara tatap muka, melalui media sosial, dan media elektronik lainnya. Kepuasan pelanggan diukur dengan melihat komentar melalui media sosial Instagram, ada juga melalui kolom review produk dari Tokopedia.
\end{abstract}

Kata Kunci: Strategi Komunikasi, Brand Lokal, Komunikasi Pemasaran. 


\section{Pendahuluan}

Indonesia adalah negara yang kaya akan tradisi dan memiliki impian yaitu dengan mengembangkan dan memajukan tradisi. Semakin pesatnya kemajuan teknologi di Indonesia membuat kebanyakan pengusaha ikut serta dalam memanfaat perkembangan teknologi seperti media sosial yang dijadikan platform untuk memasarkan produk mereka. Menurut Boyd, sosial media adalah perangkat lunak yang membuat individu ataupun komunitas agar dapat berbagi, berkumpul, berkomunikasi (dalam Nasrullah, 2015). Sama halnya dengan meningkatkan brand awareness yang harus dilakukan seorang pengusaha brand lokal, juga memerlukan strategi komunikasi yang tepat.

Menurut Middleton, strategi komunikasi adalah penggabungan terbaik dari seluruh poin penting dalam komunikasi yang dibuat agar mencapai tujuan kegiatan komunikasi yang pas (dalam Cangara 2013:61).

Menurut Kotler dan Keller (dalam Sabran, 2013:179) terdapat 8 konsep komunikasi pemasaran antara lain, identifikasi pemirsa sasaran, menentukan tujuan komunikasi, merancang komunikasi, memilih saluran komunikasi, menetapkan total anggaran komunikasi pemasaran, memutuskan bauran pemasaran, mengukur hasil, mengelola hasil pemasaran terpadu.

Penulis menggunakan penelitian terdahulu yang dilakukan oleh Kusniadji (2016) yang berjudul "Strategi Komunikasi Pemasaran Dalam Kegiatan Pemasaran Produk Consumer Goods (Studi Kasus Pada PT Expand Berlian Mulia Di Semarang)". Penulis melihat bahwa ada keterkaitan antara penelitian terdahulu dengan penelitian yang penulis teliti sekarang.

Rumusan masalah pada penelitian ini adalah "Bagaimana strategi komunikasi pemasaran yang dilakukan pengusaha brand lokal ?”. Tujuan dari penelitian ini yaitu untuk mengetahui strategi komunikasi pemasaran yang dilakukan pengusaha brand lokal.

\section{Metode Penelitian}

Pendekatan penelitian yang digunakan oleh penulis adalah pendekatan penelitian kualitatif. Pendekatan kualitatif merupakan penelitian yang mempunyai landasan pada filsafat postpositivisme, dan digunakan untuk melakukan penelitian kepada kondisi obyek alamiah, dimana peneliti adalah selaku informan kunci, serta data yang dikumpulkan memakai teknik yang dilakukan secara gabungan, analisa data bersifat induktif, atau hasil pendekatan penelitian kualitatif lebih dominan untuk makna dari pada generalisasinya (Sugiyono, 2014:9).

Studi kasus adalah penelitian kualitatif yang mengutamakan pada pencarian makna, menganalisis proses dan mendapatkan pengertian serta pemahaman yang mendalam dari individu, kelompok atau situasi (Emzir, 2016:20).

Metode pengumpulan data yang dilakukan oleh penulis yaitu melakukan wawancara dengan narasumber, melakukan observasi secara tidak langsung dan penelusuran melalui buku dan sumber online. Terdapat data primer dan data sekunder dalam penelitian ini. Data primer berupa informasi yang diunggah oleh Fine Finest Hour 
dan Your Apparel di media sosial, sedangkan data sekunder berupa transkrip hasil wawancara oleh narasumber. Yang menjadi narasumber dalam penelitian ini adalah Meittha Dhamaveianka dan Novita selaku pemiliki brand lokal Fine Finest Hour serta Velix selaku pemilik brand lokal Your Apparel.

Penulis melakukan analisis dari wawancara berupa percakapan dan dicatat dalam teks tertulis. Langkah pertama yang penulis lakukan adalah kemudian melakukan wawancara dengan narasumber dan melakukan observasi yang berkaitan dengan masalah penelitian. Lalu penulis mencari data-data melalui media sosial yang digunakan kedua brand lokal dan yang terakhir penulis menganalisis data-data yang diperoleh untuk mencari kesimpulannya.

Triangulasi dengan sumber data dalam penelitian ini dilakukan dengan membandingkan data hasil pengamatan yang penulis lakukan dengan data hasil wawancara. Melalui triangulasi dengan sumber data ini, penulis melakukan perbandingan dan pengecekan secara mendalam. Penulis melakukan triangulasi sumber data dengan mewawancarai dua orang konsumen brand Fine Finest Hour dan brand Your Apparel. Kedua konsumen tersebut sudah memiliki pengalaman berbelanja di masing-masing brand lokal. Dua konsumen tersebut adalah Janice selaku konsumen Fine Finest Hour dan Anthony selaku konsumen Your Apparel.

\section{Hasil Temuan dan Diskusi}

Penulis melakukan wawancara dengan brand clothing lokal Fine Finest Hour dan Your Apparel, karena kedua brand memiliki kewajiban untuk melakukan fungsi pengendalian dalam rangka memastikan bahwa visi dan misi perusahaan dilakukan secara benar dan konsisten. Selain melakukan pengendalian, kedua brand lokal ini juga melakukan beberapa kegiatan untuk menaikan citra perusahaan seperti kegiatan corporate social responsibility.

Berdasarkan hasil temuan dan diskusi yang penulis teliti, ada beberapa pembahasan mengenai strategi komunikasi pemasaran yang dilakukan oleh pengusaha brand lokal, yaitu Identifikasi Pemirsa Sasaran, Menentukan Tujuan Komunikasi, Merancang Komunikasi, Memilih Saluran Komunikasi, Menetapkan Total Anggaran Komunikasi, Memutuskan Bauran Komunikasi Pemasaran, Mengukur Hasil, Mengelola Hasil Pemasaran Terpadu.

Dari beberapa strategi komunikasi pemasaran yang dilakukan kedua perusahaan, kegiatan yang paling efektif yaitu endorsement. Bedasarkan hasil observasi yang penulis teliti, media sosial merupakan komunikasi pemasaran yang sangat efektif untuk berjualan. Fine Finest Hour dan Your Apparel dapat meluaskan pasar mereka melalui media sosial yang aktif mengikuti zaman. Hal tersebut juga didukung melalui pernyataan dari owner kedua perusahaan. Meittha, Novita, dan Velix menyadari bahwa dampak menggunakan kegiatan endorsement membuahkan hasil yang berpengaruh baik bagi perusahaan.

Dalam penelitian ini, penulis akan menyebut Meittha sebagai Narasumber I, Novita sebagai Narasumber II. Meittha dan Novita adalah pemilik dari brand lokal Fine Finest Hour. Penulis juga akan menyebut Velix sebagai Narasumber III. Velix adalah pemilik dari brand lokal Your Apparel. 
Berdasarkan hasil wawancara penulis dengan Narasumber I mengatakan, "Karena sekarang kan usaha yang banyak rame kan endorse yah, apalagi endorse nya ke orang yang udah dikenal banyak orang banget, pasti nanti endorse sih kalo udah agak jalan" (Meittha).

Berdasarkan hasil wawancara penulis dengan Narasumber II mengatakan, "Tema yang pertama ini self-love. Target utama ku kan anak-anak muda milenial gitu kan, terus kalau diliat dari permasalahan sosial zaman sekarang, anak-anak muda sekarang tuh suka insecure sama diri sendiri. Jadi aku bikin logonya tuh menggambarkan pikiran anak-anak milenial jaman sekarang menghancurkan pikirannya sendiri tapi seharusnya tuh mereka menjadikan pikiran itu sebagai batu loncatan gitu biar bisa jadi lebih baik lagi, dan pada akhirnya mereka bisa mencintai diri sendiri” (Novita).

Berdasarkan hasil wawancara penulis dengan Narasumber III mengatakan, "Ya sebenernya kan produk Your Apparel ini kan baru berjalan lagi ya sekitar 4-5 bulan itu pun dipotong masa produksi dari produk yang kita publish sekarang, dari 5 bulan itu masa produksi memakan waktu 1-2 bulan, sisanya memang kita pakai buat brand awareness gitu, banyak banget cara yang kita lakukan dari mulai promote Instagram, temen ke temen, endorse, ya itu buat brand awareness sih" (Velix).

Berdasarkan hasil wawancara penulis dengan Janice selaku pelanggan Fine Finest Hour mengatakan, "Konten Instagram nya menarik sih, model yang dipakai juga cocok banget jadi tertarik untuk beli".

Berdasarkan hasil wawancara penulis dengan Anthony selaku pelanggan Your Apparel mengatakan, "Informasi yang saya dapet udah cukup jelas sih, dari mulai harga nya tertera, bahan dasar kaos atau kemeja nya, fast respon juga, tapi dari size nya kalau di saya agak sempit ya”.

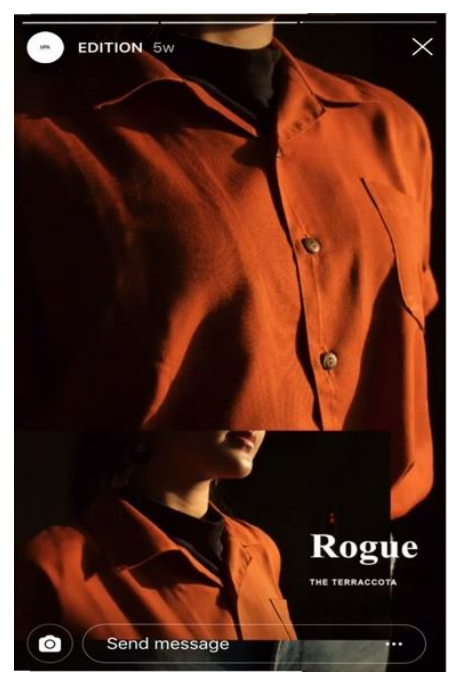

(Sumber: Instagram @YourApparel)

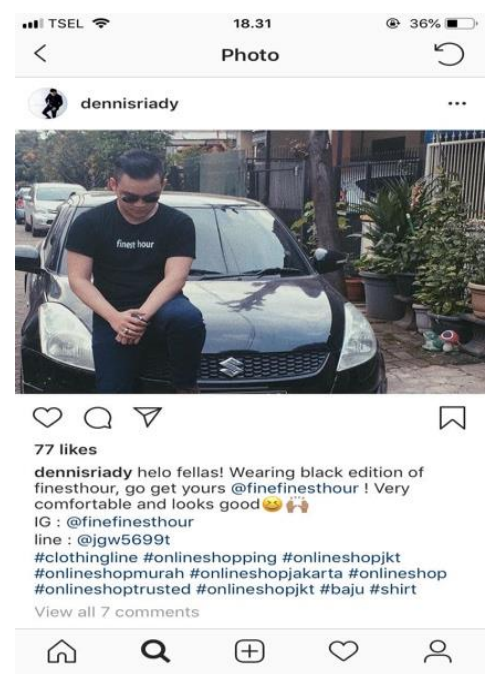

(Sumber: Instagram @FineFinestHour)

Penulis akan memaparkan beberapa hasil diskusi mengenai strategi komunikasi pemasaran yang digunakan kedua brand lokal. Ada delapan kegiatan 
Reynaldi Permana dan Roswita Oktavianti: Strategi Komunikasi Pemasaran Pengusaha Brand Lokal (Studi Kasus Pada Fine Finest Hour Dan Your Apparel)

strategi komunikasi pemasaran menurut Kotler dan Keller (dalam Sabran, 2013:179) :

a. Identifikasi Pemirsa Sasaran

Proses mengutamakan target pasar yang jelas terlihat dalam pikiran: pembeli regular produk perusahaan, pelanggan saat ini, pengambil keputusan, dan pemberi pengaruh dan masyarakat umum. Berdasarkan hasil wawancara dan observasi yang penulis teliti bahwa kedua brand lokal sudah menentukan target pasarnya yaitu anak-anak muda generasi milenial.

b. Menentukan Tujuan Komunikasi

Setelah menemukan target atau pemirsa sasaran, pemasar mengharapkan target atau pemirsa sasaran melakukan niat pembelian. Berdasarkan hasil wawancara dan observasi yang penulis teliti bahwa masing-masing brand lokal memiliki tujuan komunikasi berupa tema dari produk tersebut. Penulis melihat bahwa tujuan komunikasi dari kedua brand berbeda tetapi berhasil menciptakan keputusan pembelian pada konsumen.

c. Merancang Komunikasi

Apa yang akan dikatakan (strategi pesan), bagaimana konsep atau cara menyelesaikan (strategi kreatif), serta siapa yang harus mengatakannya (sumber pesan). Berdasarkan hasil wawancara dan observasi yang penulis teliti, kedua brand lokal kreatif dalam menyusun strategi komunikasi pemasaran terhadap produknya.

d. Memilih Saluran Komunikasi

Menentukan saluran komunikasi yang efisien untuk membawa pesan menjadi semakin sulit apabila saluran komunikasi semakin terpecah dan sesak. Berdasarkan hasil wawancara dan observasi yang penulis teliti, kedua brand lokal memiliki persamaan dalam memilih sarana komunikasi. Kedua brand lokal menggunakan media sosial untuk berjualan dengan alasan menekan budget dan efisiensi penggunaan teknologi komunikasi.

e. Menetapkan Total Anggaran Komunikasi Pemasaran

Beberapa keputusan yang paling sulit adalah menentukan seberapa besar uang yang harus dikeluarkan dalam komunikasi pemasaran, industri dan perusahaan memiliki pengeluaran untuk komunikasi pemasaran yang sangat beragam. Berdasarkan hasil observasi dan wawancara yang penulis lakukan, kedua brand lokal menetapkan total anggaran secara detail.

f. Memutuskan Bauran Komunikasi Pemasaran

Dalam satu industri yang sama, setiap perusahaan memiliki perbedaan dalam pilihan dan saluran media mereka. Berdasarkan hasil wawancara penulis dengan narasumber kedua brand lokal, bahwa kegiatan bauran pemasaran sudah direncanakan sebelum memulai bisnis. 
g. Mengukur hasil

Setelah mengaplikasikan rencana komunikasi pemasaran, pemasar diharuskan mengukur dampaknya terhadap target pemirsa sasaran. Penulis melihat bahwa hasil kepuasan terhadap konsumen mengenai kedua brand lokal ini baik dan kedua brand melakukan pengukuran hasil melalui komentar dari media sosial baik Instagram, maupun lapak online Tokopedia.

h. Mengelola Hasil Pemasaran Terpadu

Komunikasi pemasaran terpadu ialah konsep rencana komunikasi pemasaran yang mengakui nilai tambah rencana komprehensif. Penulis melihat bahwa kedua brand lokal tersebut sadar terhadap konsistensi produk yang dikeluarkan.

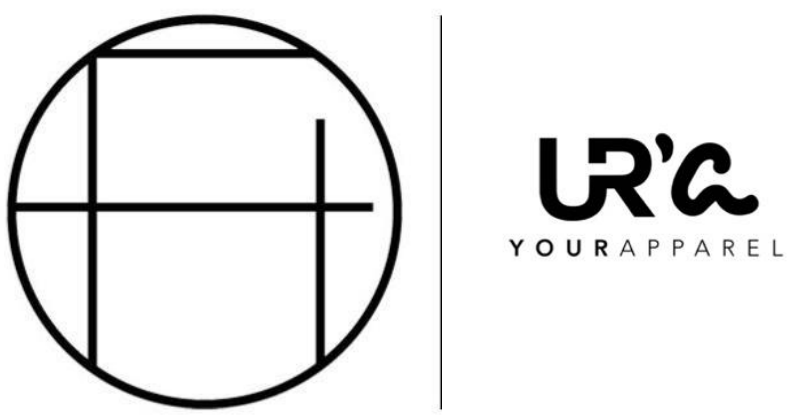

Gambar 1. Logo Fine Finest Hour dan Logo Your Apparel Sumber: (Dokumentasi brand lokal Fine Finest Hour dan Your Apparel)

\section{Simpulan}

Berdasarkan hasil penelitian yang penulis lakukan terhadap brand clothing lokal, penulis merangkum sejumlah strategi komunikasi yang dilakukan pengusaha brand lokal. Pertama, kedua brand memiliki target anak muda maka pengusaha menggunakan media sosial Instagram. Kedua, brand lokal harus memiliki tema atau ciri khas yang dekat dengan anak muda. Ketiga, pengusaha mengimplementasikan tema tersebut dalam bentuk design pakaian, logo, dan sebagainya. Keempat, komunikasi dengan pelanggan dilakukan secara tatap muka, melalui media sosial, dan media elektronik lainnya. Kelima, pengusaha mencatat semua biaya pengeluaran yang terpakai untuk pemasaran produk. Keenam, pengusaha brand lokal menggunakan beberapa bauran pemasaran yaitu produk, tempat, harga, dan promosi. Ketujuh, kepuasan pelanggan diukur dengan melihat komentar melalui media sosial Instagram, ada juga melalui kolom review produk dari Tokopedia. Kedelapan, pengusaha brand lokal konsisten dalam tema yang ditentukan, tetapi ada juga yang sempat vakum karena kurang konsisten terhadap identitas produknya dan melakukan re-branding. Dari seluruh kegiatan pemasaran tersebut, penulis menyimpulkan bahwa kegiatan yang paling dominan diperhatikan oleh kedua perusahaan yaitu memilih saluran media komunikasi dan mengukur hasil kepuasan pelanggan. 
Reynaldi Permana dan Roswita Oktavianti: Strategi Komunikasi Pemasaran Pengusaha Brand Lokal (Studi Kasus Pada Fine Finest Hour Dan Your Apparel)

\section{Ucapan Terima Kasih}

Ucapan terima kasih yang penulis berikan kepada para narasumber untuk meluangkan waktunya dan memberi informasi kepada penulis selama proses pengumpulan data untuk penelitian ini. Penulis juga mengucapkan terima kasih yang sebesar-besarnya kepada Dosen Pembimbing dan teman-teman serta Fakultas Ilmu Komunikasi Universitas Tarumanagara.

\section{Daftar Pustaka}

Cangara, Hafied.2013. Perencanaan \& strategi Komunikasi. Depok: PT. Raja Grafindo Persada.

Emzir. 2016. Metodologi Penelitian Kualitatif Analisis Data. Jakarta: Pt Raja Grafindo Persada .

Kotler, Philip and Kevin Lane Keller. 2013. Manajemen Pemasaran.( Edisi 13). Jilid 1. Terjemahan Bob Sabran. Jakarta: Erlangga.

Kusniadji, Suherman. 2016. Strategi Komunikasi Pemasaran Dalam Kegiatan Pemasaran Produk Consumer Goods (Studi kasus Pada PT Expand Berlian Mulia Di Semarang). Jurnal Komunikasi, Volume 8, No, 1, 83-98.

Nasrullah, Rulli. 2015. Media Sosial; Persfektif Komunikasi, Budaya, dan Sosioteknologi. Bandung : Simbiosa Rekatama Media.

Sugiyono. (2014). Metode Penelitian Pendidikan Pendekatan Kuantitatif, Kualitatif, dan $R \& D$. Bandung: Alfabeta. 